\title{
Flourish or perish: The UK academic surgeon model
}

Daniel Paul Fudulu, MD, PhD, and Gianni Davide Angelini, MD

\section{THE ACADEMIC SURGEON: HARD TO BE BUT GREAT TO BE}

Progress in cardiac surgery will continue to be driven by surgeons who are willing to dedicate their time to answering pertinent research questions in their field. If we reflect on the great discoveries that made open-heart surgery possible, the heart-lung machine, or development of myocardial protection, for example, these would not have been possible without an inquisitive mind and significant time spent in the research laboratory. ${ }^{1,2}$ Although surgeons must dedicate a significant amount of their time and stamina to clinical work, they are in a unique position to identify clinical problems, understand their mechanisms of action using basic science, and take possible solutions back into everyday clinical practice.

However, succeeding in this dual role of "surgical investigator" is no easy undertaking, and you need to have the drive, discipline, and focus. It is less arduous to go and do an operation than to develop research ideas, write a grant, publish a paper, or be responsible for the mentoring and the supervision of your research group. Despite these challenges, working with a diverse multidisciplinary research team to improve patient care, the opportunity to travel around the world to present the ideas that are generated, networking, and being a voice at the forefront of the research in your field are unparalleled satisfactions of being an academic surgeon.

We have read with great interest the work by Ikonomidis and colleagues ${ }^{3,4}$ and Lawton ${ }^{5}$ in this Journal. They discuss the challenges and the solutions to prevent the extinction of the surgeon-scientists in the United States. We herein continue to share our thoughts about the UK model of the academic surgeon in general. How do we produce academic surgeons? Who and how we should run surgical research? What are the research topics on which we should focus?

From the Department of Cardiac Surgery, Bristol Heart Institute, Bristol University, Bristol Royal Infirmary, Bristol, United Kingdom.

This work was funded/supported by the British Heart Foundation and the National Institute for Health Research Biomedical Research Centre at University Hospitals Bristol National Health Service Foundation Trust and the University of Bristol.

Received for publication May 12, 2020; revisions received June 10, 2020; accepted for publication June 19, 2020; available ahead of print July 18, 2020.

Address for reprints: Gianni D. Angelini, MD, Bristol Heart Institute, Bristol University, Bristol Royal Infirmary, Bristol BS28HW, United Kingdom (E-mail: g.d. angelini@bristol.ac.uk).

J Thorac Cardiovasc Surg 2021;162:1590-4

$0022-5223 / \$ 36.00$

Copyright (c) 2020 by The American Association for Thoracic Surgery

https://doi.org/10.1016/j.jtcvs.2020.06.140

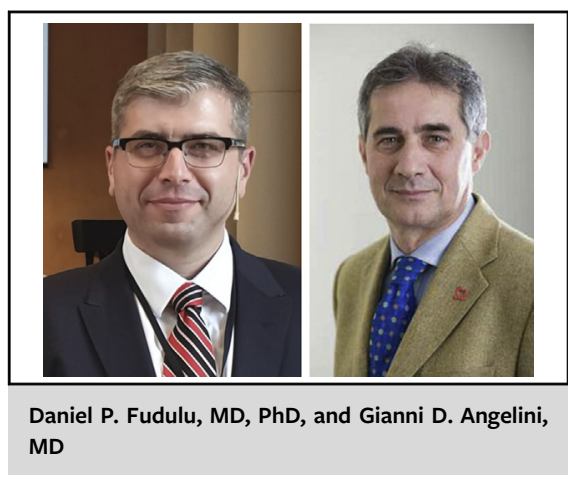

\section{CENTRAL MESSAGE \\ Academic cardiac surgery is a specialty that demands drive and discipline. High-output research requires dedicated and pro- tected time.}

This Invited Expert Opinion provides a perspective on the following paper: J Thorac Cardiovasc Surg. 2020 May;159(5):1917-1920. https://doi.org/ 10.1016/j.jtcvs.2019.10.179.

See Commentaries on pages 1595 and 1596.

\section{AMATEUR OR PROFESSIONAL?}

In a commentary in the Lancet in the 1990s, Horton ${ }^{6}$ described surgical research as "a comic opera," highlighting that only $7 \%$ of the articles in surgical journals reported data from randomized trials in the United Kingdom. During that time, the British Heart Foundation (BHF) was the leading charity providing funds for cardiovascular research, whereas the Medical Research Council (MRC) and the Wellcome Trust (WT) were funding a much broader portfolio. There were 4 BHF professorial chairs in cardiac surgery in the United Kingdom and little incentive to embark on a research career, not the least because of the great demand for private practice. The waiting list for an elective cardiac surgery procedure in the National Health Care System (NHS) was up to 12 to 16 months.

Research in cardiac surgery has certainly evolved to the extent that we now have dedicated, university academic cardiac surgeons leading successful units, but also honorary NHS academics actively engaging in research. Highquality research outputs come from the combination of 
these 2 entities, but the essential determinant of success is funding that pays the dedicated research time or "protected time" of the surgeon and the related research costs. Trying to do research between theater cases or after a draining clinical day is unproductive, frustrating, and is unlikely to lead to high-impact research. As always, some exceptional individuals can combine a high-volume surgical practice with very productive research. However, it is not only a matter of what you can do but how you want to live your life. While some surgeons find fulfillment in such busy roles, others may wish to benefit from a better work-life balance, including more time for family and to develop other interests outside academia or surgery. There are also cultural differences that could influence how much time we choose to spend at work, and in the United Kingdom, there are regulations that restrict the maximum weekly working hours. ${ }^{7}$

Non-clinical researchers and non-surgical clinical specialties, one may argue, have more time to spend in preparing a grant application and polishing it, so surgeons must reach to this very high standard when they compete for funding. It is the difference between playing the game at a professional versus at an amateur level.

As surgeons, we take pride in our easily accessible data on surgical outcomes to the general public, and many ask themselves if they can be good at both research and maintaining their operating skills. In the United Kingdom, academic cardiac surgeons have a reduced clinical workload by approximately $60 \%$. While a full-time NHS cardiac surgeon will undertake approximately 160 to 180 cardiac surgery cases a year, an academic surgeon will do around 100 to 120 procedures, so we do not think there is a risk of deskilling.

\section{BUILDING RESEARCH INTO TRAINING}

To achieve a clinical academic/surgical workforce with dedicated research time, significant structural changes had to be implemented in the UK clinical training system in the last 2 decades. The result was the creation of a product pipeline. The product is the academic surgeon or a clinical academic. These are trained doctors who are employed by the universities to undertake relevant clinical or basic research and teaching in parallel to their NHS clinical practice. The Saville report published by the Academy of Medical Sciences in $2000^{8}$ was the first document to outline recommendations for the creation of a clear career structure in academic medicine. An essential aspect of the scheme was the creation of the tenure-track status for the post holder. This resulted in the implementation of Clinician Scientists Fellowships for doctors that were keen to pursue postdoctoral research. The MRC ${ }^{9}$ is the main funder for this type of awards, whereas the $\mathrm{WT}^{10}$ funds a similar type of fellowship (Research Career Development Fellowships). Such fellowships fund personal research time for up to 5 years and have an allowance for research consumables that can support the aspiring academic up to senior positions. These fellowships are ideally suited for people who have already made the decision to pursue an academic carrier but not for those still undecided, since they need to reduce their clinical training temporarily. The scheme is designed to support the dual academic-clinician career pathway, offering talented researchers the flexibility to dedicate up to $20 \%$ of their time to clinical sessions to maintain clinical skills.

Later, the Walport ${ }^{11}$ report, published in 2005, recommended the creation of an academic training pathway built within the clinical training (Figure 1). The success of the so-called integrated academic training pathway relied on the collaboration of 3 main bodies (clinical academic triangle): the employers (NHS/University/Industry), the training bodies (Royal Colleges, Postgraduate Deans, Postgraduate Medical Education and Training Board), and the research funders.

The first exposure to science can occur during medical school when some students undertake an intercalated BSc (Bachelor in Science) or an MSc (Master in Science). Few universities offer students an integrated $\mathrm{PhD}$ within the clinical training $(\mathrm{MBPhD}$ programs). The first exposure of the trainee to research in the immediate postgraduate period is by pursuing an academic foundation training program that permits a research block (usually 4 months) built within the 2 years of clinical training. Three-year Academic Clinical Fellowships allow the trainee to spend up to $25 \%$ of their time in research after being selected into the specialty training program either at Specialty Training ST3 level or for run-through training programs, at ST1 level. This dedicated research time allows the trainee to develop research interests, undertake some research methods training, and generate research data to write a grant application for a $\mathrm{PhD}$. Therefore, the substantial funding of $\mathrm{PhDs}$ for surgeons by the National Institute for Health Research (NIHR), the BHF, the WT, or Cancer Research UK played a central role in the shaping of the academic surgeon.

Upon award of the PhD, the trainee can further continue their academic training pathway by applying for an Academic Clinical Lectureship (ACL) (a limited number a year are awarded by the NIHR after a national competition between all specialties). The ACL is awarded toward the latter end of the higher specialty training but not too close to completion of training. During the 4-year ACL post, there is $50 \%$ protected time for research that, in the craft specialties, usually necessitates some extension of the certificate of completion of the training award date. This position gives the trainee the best possible opportunity to build a competitive research portfolio and to apply for a senior clinical lectureship position at the consultant level and to continue the road to a professorship. During the clinical lectureship, the trainee has access to mentorship by a fellow of the Academy of Medical Sciences. ${ }^{12}$ The Academy also runs a starter grants program, ${ }^{13}$ in collaboration with the WT, the BHF, the MRC, and other funders. This enables the young lecturers, situated in the vulnerable post-doc phase, to support their research project and to 


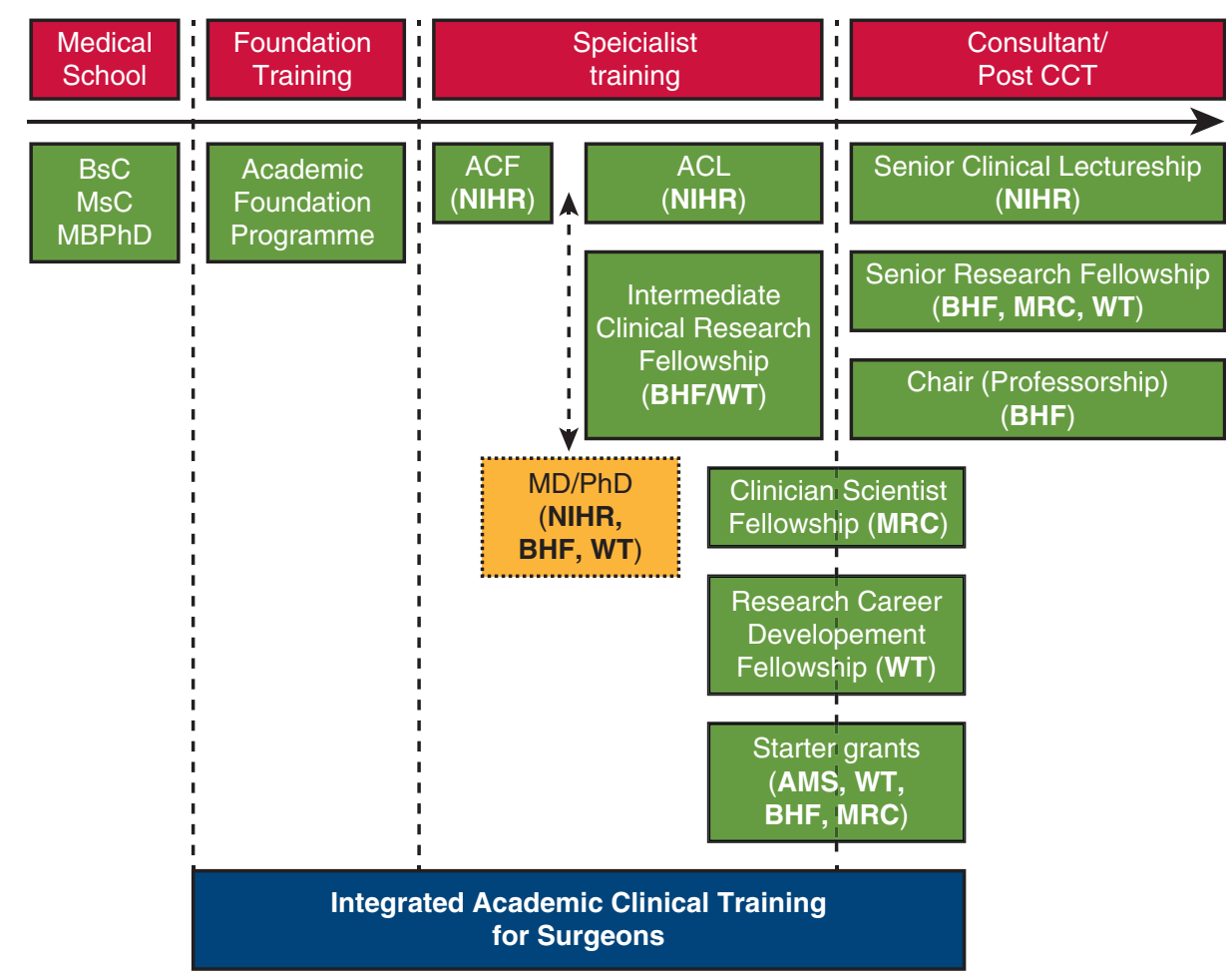

FIGURE 1. The integrated clinical academic pathway available for surgeons with various funding opportunities depending on the stage of career progression (list of funding bodies is not exhaustive). $C C T$, Certification of Completion of Training; $A C F$, Academic Clinical Fellowship; ACL, Academic Clinical Lectureship; $B H F$, British Heart Foundation; WT, Welcome Trust; $I H R$, National Institute for Health and Research; $M R C$, Medical Research Council; $A M S$, The Academy of Medical Sciences.

continue to accumulate more data to strengthen their bid for more senior, longer-term research fellowships.

Having protected research time away from clinical pressures is one of the challenges of the academic pathway, as highlighted in a national survey that showed that $62 \%$ of academic trainees had been asked to cover clinical duties during their research time. ${ }^{14}$ Another challenge is the limited and very competitive senior university positions available for trainees to progress, particularly in cardiac surgery. ${ }^{15}$ In the last 5 years, only 2 ACL cardiac surgeons progressed to an associated professor position. However, even if the trainees do not progress from Academic Clinical Fellowship to ACL or further to senior clinical lectureships, the time they spend doing research is invaluable and likely to influence their future clinical career where they can still contribute to network research recruiting to trials.

The main funder of the integrated academic training pathway is the NIHR. The NIHR is the largest national clinical research funder in Europe and injects approximately $£ 1$ billion (US\$ 1.3 billion) every year into clinical research. ${ }^{16}$ Indeed, the establishment of the NIHR was another fundamental structural change that enabled the research to flourish alongside clinical progression.

Similar to the NIHR-ACL scheme, the Intermediate Clinical Research Fellowships developed by the $\mathrm{BHF}^{17}$ or $\mathrm{WT}^{18}$ can pay the research time of the trainee during the final years of training as they progress up to consultant level. Upon completion of their training, the BHF Senior Research Fellowships, ${ }^{19}$ taken up on a part-time employment basis, can further support the academic surgeon to reach associated professorship or professorial chair level. Similarly, senior research fellowships are also funded by the NIHR, MRC, or the WT.

The BHF also funds personal chairs ${ }^{20}$ that are usually awarded to senior investigators in clinical or basic cardiovascular science that generate high impact research. Chairs are awarded initially for 10 years and re-evaluated every 5 years. At present, there are 2 adult cardiac surgery and 1 pediatric heart surgery BHF chairs in the United Kingdom. Between 1980 and 2000, the BHF awarded 84 cardiovascular surgery grants worth around $£ 14 \mathrm{~m}$. These included 17 fellowships, among which 4 BHF Professors. Since 2001, the BHF has awarded 96 cardiovascular surgery grants worth more than $£ 48 \mathrm{~m}$. These included 26 fellowships, among which $3 \mathrm{BHF}$ Professors (BHF, personal communication, 2020).

\section{THE RESEARCH NETWORKS}

The most effective way of conducting research is by building a local, national, and possibly international research network through which academic surgeons can coordinate relevant studies. It is not necessary for a trainee to be an "academic surgeon" to be involved in research projects. The 
limited number of university academic cardiac units prevents this from happening. Research networks, however, allow all surgeons to take part whereas senior clinical academic surgeons with research expertise and leadership coordinate these efforts and ensure that the study is conducted to the highest standard. One good example is the NIHR Clinical Research Network (CRN), ${ }^{21}$ which provides support for clinicians to take part in studies and is made up of 15 Local CRNs across England and covers 30 specialties. One of the successes of this initiative was undoubtedly the introduction of the portfolio study concept. ${ }^{22}$ If a study is recognized as an NIHR-CRN Portfolio study, the NHS hospital will receive funding on entering a patient to a randomized controlled trial but also for observational cohort studies. Research into cardiovascular disease, for example, can also be conducted in a dedicated infrastructure-Biomedical Research Centres (BRCs). There is a total of 10 NIHR-BRCs ${ }^{22}$ partnerships between England's leading NHS organizations and universities; Scotland and Wales have a comparable setup. The central role of these units is to allow effective collaboration between the best scientists and clinicians and to translate lab-based discoveries into medical technology, diagnostics, or therapeutics.

To host a BRC is a considerable plus and prestige for any NHS hospital. Most importantly, it creates a financial incentive for the hospital, which can, in return, pay for dedicated research time to the individuals who are actively collaborating and recruiting into studies. This also gives them the time and opportunity to develop their research projects.

The Royal College of Surgeons ${ }^{22}$ has established a similar network to the NIHR, through 7 surgical trials units across the United Kingdom. There are surgical specialty leads that coordinate the research in various fields as part of a multidisciplinary team. Examples of such collaborative efforts were the TITRe $2,{ }^{23}$ a randomized trial investigating restricted versus liberal blood transfusion in cardiac patients, that recruited from 17 centers in the United Kingdom or other trials currently open for recruitment such as the GAP study or INSPIRE trials. ${ }^{24}$ The GAP study looks at the effectiveness, cost-effectiveness, and safety of gabapentin versus placebo as an adjunct to pain regimens in surgical patients. The INSPIRE trial will assess the effectiveness and cost-effectiveness of inspiratory training for reducing postoperative pulmonary complications.

National data have shown a steady increase by year in the number of NIHR portfolio trials (from 101 in 2011/2012 to 357 in 2017/2018) and RCS surgical trials (from 11 in 2011/ 2012 to 66 in 2017/2018) open for recruitment (NIHRCRN, personal communication, 2020).

Data science is another example of multidisciplinary collaboration, demonstrating the need to look even further afield to disciplines we are not accustomed to interacting with. The evolving area of big data and the application of artificial intelligence, particularly the application of machine learning algorithms to study cardiac surgery outcomes, is a rapidly growing area of research. ${ }^{25}$
While there is no direct financial benefit for surgeons taking part in research, it is very rewarding to be part of a research productive department and authorship in papers.

\section{THE SURGEON-BASIC SCIENTIST, AN EXTINCT SPECIES?}

Surgeons will always be at the forefront of clinical research that they will find straightforward, but they also need to embrace basic science research. ${ }^{25}$ A surgeon with a genuine interest in fundamental research needs to have some basic science exposure, ideally during a doctoral program. This can be achieved by working as part of a multidisciplinary research group with more opportunities to interact with basic scientists. Working on an in vivo animal model or in a cell-culture model, doing yourself the polymerase chain reaction or your western blotting can give you a unique insight into what it takes to be a scientist. You might not get to do this long term, but it teaches you the approaches you may choose in your future research (in vitro, in vivo, or clinical translation). Charities such as the BHF, NIHR, WT, or MRC welcome funding of surgical studies with a mechanistic scientific component. ${ }^{26,27}$

Basic science does not always yield positive results, and success usually comes from low-volume high-quality publications, which often add another piece to the knowledge pool.

In the surgical world, we like to talk about clinical research that is very pertinent to our day-to-day practice. Developing a research interest for molecular or physiology science might make the surgeon-scientist well known in the "science" world but might isolate him from the "surgery" world. Studying stress physiology related to surgery ${ }^{28}$ can be a fascinating area for neuroendocrinologists, pediatric intensivists, or basic stress scientists, while surgeons might find such subjects less appealing. All of these aspects, however, should not deter from embracing the surgeon-scientist model.

\section{ASKING THE RIGHT QUESTION}

It is very easy to deviate from the course of identifying relevant questions in your field that ultimately benefit patients. The Heart Surgery Priority Setting Partnership has recently established 10 top priorities for research across the United Kingdom from the perspective of patients, carers, and clinicians. ${ }^{29}$ Finding a research area that you enjoy and identify with is the main key to success. However, a better understanding of the research questions that will lead to progress also requires knowledge of basic and translational research approaches, hence the need for a surgeon-basic scientist model as part of the mix. Successful academic surgeons should embrace and understand all aspects of research and make them part of their research portfolio.

\section{ARE YOUR HEART AND MIND COMMITTED?}

It is estimated that approximately 200 billion, or $85 \%$ of the invested money in research is wasted globally. ${ }^{24}$ Therefore, the first question a trainee should ask himself/herself 
must be "are you doing this because you have a genuine interest in research? Do you want to understand the challenges you face in your everyday clinical practice and find better ways of tackling them? Or, are you doing research because you must tick another box in your CV?" If your heart is not in the task, you are unlikely to make a worthwhile contribution, however hard you work. The competition for funding remains fierce; if you fail at the first attempt, do not give up because this has happened to all of us. You are up against lots of other people applying for research funding, and even the most successful researchers expect to be awarded only 1 in 3 of the grants for which they apply. While there are funding opportunities aimed at early career investigators, the approximate success rates of a grant application to UK funding agencies for researchers transitioning to independence are in the range of $20 \%$ to $25 \% .{ }^{30}$ Remember that the essential things in research are dedication, commitment, and perseverance.

"The surgical investigator must be a bridge tender

channeling knowledge from biological science to the patients' bedside and back again. He traces his origins from both ends of the bridge."

-Francis Daniels Moore (1913-2001)

\section{Conflict of Interest Statement}

The authors reported no conflicts of interest.

The Journal policy requires editors and reviewers to disclose conflicts of interest and to decline handling or reviewing manuscripts for which they may have a conflict of interest. The editors and reviewers of this article have no conflicts of interest.

\section{References}

1. Cooley DA, Frazier OH. The past 50 years of cardiovascular surgery. Circulation. 2000;102(20 suppl 4):IV87-93.

2. Hearse DJ, Stewart DA, Braimbridge MV. Cellular protection during myocardial ischemia. The development and characterization of a procedure for the induction of reversible ischemic arrest. Circulation. 1976;54:193-202.

3. Ikonomidis JS. Solutions for surgeon-scientists. J Thorac Cardiovasc Surg. 2019; 159:1917-20.

4. Ikonomidis JS, Menasché P, Kreisel D, Sellke FW, Woo YJ, Colson YL. Attrition of the cardiothoracic surgeon-scientist: definition of the problem and remedial strategies. J Thorac Cardiovasc Surg. 2019;158:504-8.

5. Lawton JS. Commentary: Opposing forces will lead to surgeon scientist extinction. J Thorac Cardiovasc Surg. 2020;159:1921-2.

6. Horton R. Surgical research or comic opera: questions, but few answers. Lancet. 1996;347:984-5.

7. GOV.UK. Maximum weekly working hours: opting out of the 48 hour week. Available at: https://www.gov.uk/maximum-weekly-working-hours/weekly-max imum-working-hours-and-opting-out. Accessed May 28, 2020.

8. The Academy of Medical Sciences. Tenure-Track Clinician Scientist: a new career pathway to promote recruitment into clinical academic medicine; 2000. Available at: https://acmedsci.ac.uk/file-download/34691-Clinic.pdf. Accessed May 11, 2020.

9. Clinician Scientist Fellowship (CSF) - skills \& careers - Medical Research Council. Available at: https://mrc.ukri.org/skills-careers/fellowships/clinical-fel lowships/clinician-scientist-fellowship-csf/. Accessed May 1, 2020.
10. Research Career Development Fellowships - Grant Funding | Wellcome. Available at: https://wellcome.ac.uk/grant-funding/schemes/research-career-develop ment-fellowships. Accessed May 1, 2020.

11. Donaldson L, Campbell H, Armstrong M, Hall R, Bedi R, Wilson D, et al. Medically- and dentally-qualified academic staff: recommendations for training the researchers and educators of the future. UK Clin Res Collab. 2005.

12. Mentoring | The Academy of Medical Sciences. Available at: https://acmedsci. ac.uk/grants-and-schemes/mentoring-and-other-schemes/mentoring-programme. Accessed May 1, 2020.

13. Starter Grants for Clinical Lecturers | The Academy of Medical Sciences. Available at: https://acmedsci.ac.uk/grants-and-schemes/grant-schemes/starter-grants. Accessed May 1, 2020.

14. Blencowe NS, Glasbey JC, McElnay PJ, Bhangu A, Gokani VJ, Harries RL. Integrated surgical academic training in the UK: A cross-sectional survey. Postgrad Med J. 2017;93:581-6.

15. UK Cardiothoracic Surgery Workforce Report. 2019. Available at: https://scts. org/released-workforce-report-2019/. Accessed May 1, 2020.

16. Jones MM, Kamenetzky A, Manville C, Ghiga I, MacLure C, Harte E, et al. The National Institute for Health Research at 10 years: an impact synthesis: 100 impact case studies. Rand Heal Q. 2017;6:13.

17. Intermediate Clinical Research Fellowships funded by BHF. Available at: https://www.bhf.org.uk/for-professionals/information-for-researchers/what-wefund/intermediate-clinical-research-fellowships. Accessed May 1, 2020.

18. Intermediate Clinical Fellowships (Closed) | Wellcome. Available at: https:// wellcome.ac.uk/grant-funding/schemes/intermediate-clinical-fellowships. Accessed May 1, 2020.

19. Senior Clinical Research Fellowships funded by the BHF. Available at: https:// www.bhf.org.uk/for-professionals/information-for-researchers/what-we-fund/se nior-clinical-research-fellowship. Accessed May 1, 2020.

20. Chairs and Programme Grants | BHF. Available at: https://www.bhf.org.uk/f or-professionals/information-for-researchers/what-we-fund/personal-chairs. Accessed May 1, 2020.

21. Clinical Research Network | NIHR. Available at: https://www.nihr.ac.uk/explo re-nihr/support/clinical-research-network.htm. Accessed May 1, 2020.

22. Cardiovascular Disease | NIHR. Murphy GJ, Pike K, Rogers CA, Wordsworth S, Stokes EA, Angelini GD, et al. Liberal or restrictive transfusion after cardiac surgery. $N$ Engl. Available at: https://www.nihr.ac.uk/explore-nihr/specialties/ cardiovascular-disease.htm. Accessed May 1, 2020.

23. Murphy GJ, Pike K, Rogers CA, Wordsworth S, Stokes EA, Angelini GD, et al. Liberal or restrictive transfusion after cardiac surgery. N Engl J Med. 2015;372: 997-1008.

24. Studies. Available at: http://cteu.bris.ac.uk/our-studies/?trialType=Cardiac-sur gery-adult. Accessed May 1, 2020.

25. Chalmers I, Glasziou P. Avoidable waste in the production and reporting of research evidence. Lancet. 2009;374:86-9.

26. Mumford AD, Harris J, Plummer Z, Lee K, Verheyden V, Reeves BC, et al. Nearpatient coagulation testing to predict bleeding after cardiac surgery: a cohort study. Res Pract Thromb Haemost. 2017;1:242-51.

27. Gibbison B, Keenan DM, Roelfsema F, Evans J, Phillips K, Rogers CA, et al. Dynamic pituitary-adrenal interactions in the critically ill after cardiac surgery. $J$ Clin Endocrinol Metab. 2020;105:1327-42.

28. Fudulu DP, Angelini GD, Papadopoulou FF, Evans J, Walker-Smith T, Kema I, et al. The Peacock study: feasibility of the dynamic characterisation of the paediatric hypothalamic-pituitary-adrenal function during and after cardiac surgery. BMC Cardiovasc Disord. 2020;20:245.

29. Heart Surgery PSP Top 10 Priorities | James Lind Alliance. Available at: http:// www.jla.nihr.ac.uk/priority-setting-partnerships/heart-surgery/top-10-priorities. htm. Accessed May 1, 2020.

30. Tabulated summary of research grant schemes and fellowship awards available to biomedical researchers transitioning to independence. Available at: https:// acmedsci.ac.uk/file-download/98853572. Accessed June 2, 2020.

Key Words: clinical academic, academic cardiac surgery, surgeon-scientist, academic surgery, academic surgeon, surgical research, integrated academic clincal training 